\title{
The Effect of Enhanced Recoveries after Surgery Protocol on the Outcomes of Patients Undergoing
} Cardiac Surgery

\author{
Ghada Shalaby Khalaf Mahran ${ }^{1}$,Mervat Anwer Abd-Aziz ${ }^{2}$, Mona Abd Elaziem Ahmed ${ }^{3}$, Ahmed M. Taha \\ Ismail $^{4}$ \& Hussein Elkhayat ${ }^{5}$ \\ 1. Assistant Professor of Critical Care and Emergency Nursing, Faculty of Nursing, Assiut University, Egypt. \\ 2. Assistant Professor of Critical Care and Emergency Nursing, Faculty of Nursing, Assiut University, Egypt. \\ ${ }^{3 .}$ Lecturer of Critical Care and Emergency Nursing, Faculty of Nursing, Assiut University, Egypt. \\ ${ }^{4 .}$ Lecturer of cardiothoracic surgery, Faculty of Medicine, Assiut University, Egypt. \\ ${ }^{5 .}$ Assistant Professor of cardiothoracic surgery, Faculty of Medicine, Assiut University, Egypt.
}

\begin{abstract}
Background: Enhanced recovery after cardiac surgery protocol is an evidence-based interdisciplinary process, which has not previously been systematically applied to cardiac surgery. Objectives: The aim of this study was to evaluate the clinical effectiveness of ERAS protocol compared with routine care on the outcomes of patients undergoing cardiac surgery. Methods: This study was conducted between January 2020 and December 2020. A total of 75 patients who underwent cardiac surgery by one surgical team were evaluated for eligibility. Five patients were excluded after the initial assessment; hence, 70 patients were randomly assigned to the ERAS protocol group and control group. Patients in the ERAS group received all elements of the ERAS protocol while patients in control group receive routine care. Tools: Preoperative assessment tool to form base line data, Intra-operative assessment tool to assess Ischemic time, bypass time, and operation time and postoperative evaluation tool to assess the patients' outcome were used in data collection .Results: The duration of ICU stay and duration of mechanical ventilation were significantly shorter in the ERAS group versus control group3.04 $\pm 0.74,2.33 \pm 0.8)$, versus $(5.82 \pm 0.61,4.64 \pm 2.13)$, respectively; $\mathrm{P}<0.001)$. Post-operative bleeding and re intubation were less in ERAS group versus control group (10 $\%, 3.33 \%)$, versus $(36.67 \%, 16.66 \%)$, respectively; $\mathrm{P}=0.03)$. Conclusions: ERAS protocol reduces the length of ICU and for patients undergoing cardiac surgery.
\end{abstract}

\section{Keywords: Cardiac surgery, Enhanced recovery, Mechanical ventilation \& Pain}

\section{Introduction:}

A variety of management strategies and protocolized care pathways have been developed during the last several decades in an effort to reduce the time required to recover from surgery (Thiele R.H etal,2015). Enhanced recovery after surgery (ERAS) is an international effort to develop perioperative programs aimed at optimizing patient outcomes and healthcare delivery efficiency (Gregory A.J et al 2020).

The first report about the concept of enhanced recovery after surgery (ERAS) was by Kehlet (Kehlet H, 1997) in 1997. Enhanced recovery is a series of evidence-based perioperative care pathways include the preoperative, intraoperative and postoperative periods (Varadhan KK, Lobo DN, Ljungqvist $\mathbf{O}$, 2010 \& Williams JB et al,2019). These pathways based on standardized practice and care with a patient-centered focus (Fleming IO et al, 2016 \& Grant MC et al 2019). Moreover, these pathways designed to reduce psychological and physiological stress response in surgical patients, maintain physiological homeostasis, lessen readmissions, minimize surgical complications, decrease morbidity, improve cost-effectiveness, and to improve and achieve rapid postoperative recovery (Scott MJ et al 2015 , Joliat GR et al 2018, Cohen $R, G$,et al 2018 \&Smith J et al, 2019).

Cardiac surgery is the specialty of medicine concerning the surgical treatment of pathologies related to the heart and thoracic aorta. The spectrum of modern cardiac surgery can be understood by its history beginning at the end of the 19th century. Since then cardiac surgery developed through the work of numerous dedicated surgeons offering more and more treatments for diverse cardiac pathology (David \& Lawrence, 2017).

Cardiac surgery represents high operative and perioperative risk requiring professional staff and advanced equipment. Conventional cardiac surgery is performed via a median sternotomy; the sternum is divided completely from the sternal notch to the xiphisternum. The operation includes cardiopulmonary bypass established by siting cannulas in the right atrium and ascending aorta. (Akowuah et al.2017).

Patients undergoing cardiac surgery experience physiological stress, an inflammatory response with potentially high complication rates. Most researches 
on ERAS have been in colorectal surgery The application of ERAS pathways have been widely increased in other surgical procedures but there is a little studies on the use of ERAS in cardiac surgery and, most of those trials were retrospective (Noss C et al, 2018 , Markham T et al,2018 \& Li M,2018). Elements of enhanced recovery could ameliorate surgical stress and would be well suited for patients undergoing cardiac surgery. Therefore, we conducted this study to evaluate the impact of an ERAS protocol in patients undergoing cardiac surgery in comparison to the conventional standard of care in our institute.

\section{Significance of the study}

During the year of 2019 and 2020 the number of patient's admitted for cardiac surgery at Assiut University cardiac hospital was 300 cases. Whatever, surgical advancement has been achieved in the field of cardiac surgery within the last 3 decades; postoperative morbidity continues to be frequent. The surgical stress response is considered to be the principal and most common factor leading to postoperative morbidity. To blunt this response, which causes a systemic release of stress hormones and inflammatory mediators, Enhanced Recovery After Surgery (ERAS) programs have been developed and have shown outstanding results.

\section{Patients and Methods}

Research design: Quasi-experimental research design .

Setting: The study was conducted at Assuit university heart hospital. The critical care unit where this study was conducted included preoperative preparation room, intraoperative room and a 12-bed postoperative ICU.

\section{Sampling:}

Patients underwent cardiac surgery were included between January 2020 and December 2020 by one surgical team.

Inclusion criteria: patients who had the following criteria were included in the study.

- Age between 18 and 60 years old

- Had a body mass index of $15-30 \mathrm{~kg} / \mathrm{m} 2$

- Receiving elective cardiac surgery.

The exclusion criteria: patients who had the following criteria were excluded from the study

- Pregnancy.

- Have infective endocarditis.

- A history of stroke or unconscious.

- An abnormal renal \& liver function test.

- Presence of endocrine disease as thyroid and adrenal diseases.

- Severe mental disorder.

- Existing pacemaker.
The total numbers of patients who underwent cardiac surgery and evaluated for eligibility were 75 . From those 75 , five patients were excluded after the initial assessment; hence, 70 patients were randomized by independent personnel based on a computer generated random digit table. Permuted block randomization was used with a block size of 2 and an allocation ratio of $1: 1$. After randomization, ten patients were excluded from the study. They refused to participate in the trial. Of the remaining 60 patients, 30 received conventional routine care, and 30 received ERAS protocol (Fig. 1).

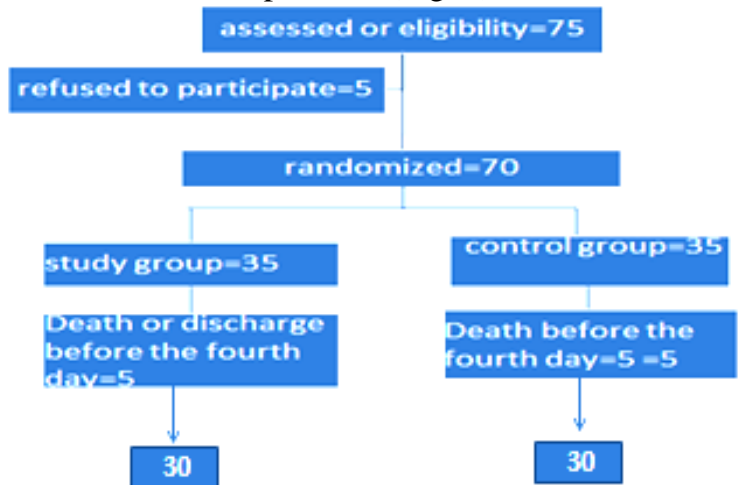

Figure 1: Consort flow chart of the study.

\section{The aim of the study}

The aim of this study was to evaluate the clinical effectiveness of ERAS protocol compared with routine care on the outcomes of patients undergoing cardiac surgery.

Hypothesis:

ERAS protocol could improve the outcomes of patients undergoing cardiac surgery

Null Hypothesis:

ERAS protocol could not improve the outcomes of patients undergoing cardiac surgery

\section{Tools:}

Five tools were used in this study after reviewing the related literatures.

Tool one: "Preoperative assessment tool"

This tool was developed by the researcher after review of literatures to assess the patient during preoperative period to form base line data. This tool compromised two parts:

Part I:-socio-demographic data and clinical data This part developed by the researcher to provide information about Patient's which includes patient's sex, age, medical diagnosis, past history, weight, height and BMI.

Part II: American society of anesthesiology physical status classification that included the following:

- I: Healthy person.

- II: Mild systemic disease.

- III: patient with severe systemic disease. 
- IV: patient with severe systemic disease that is a constant threat to life.

- V: Moribund patient who is not expected to survive without the operation.

- VI: declared brain-dead patient whose organs are being removed for donor purposes.

Tool two: "Intraoperative assessment tool:

This tool was developed by the researcher after review of literatures to assess the patient during intraoperative period.This tool compromised two parts: Part I: this part developed by the researcher to assess Ischemic time, bypass time, and operation time.

Part II: amount of blood transfusion Tool three: postoperative \& outcomes evaluation tool

This tool was developed by the researcher after review of literatures, to assess the patient conditions in the post-operative period adopted to (cheng et al, 2011). This tool compromised five parts:

Part I: "duration of mechanical ventilation and need for re-intubation"

Part II: Wound infection

Part III: Blood loss during the first 12 hours after surgery

Part IV: ICU stay

Part V: Time to first mobilization

Tool four: "visual analogue scale for pain assessment VAS pain scores ranged from 0-10: $0=$ no pain; $1-3$ $=$ mild endurable pain; $4-6=$ moderate endurable pain, patient able to sleep; $7-10=$ intense intolerable pain (Wewers M.E et al, 1990).

Tool five: "Quality of life (EuroQoL EQ-5D-3L) (adopted to Van M, 2015)

Quality of life was assessed for each patient by using the Euro QoL EQ-5D-3L questionnaire. It includes 5 dimensions: mobility, self-care, activities, pain and anxiety. The score for each dimension was: 1 for (no problem), 2 for (some problem) and 3 for (extreme problem). When the patient was physically unable to complete the questionnaires, the assessment was performed over the telephone; the questionnaire was repeated at 2, 6 weeks following discharge from hospital.

Methods:

Each patient was followed up by a research coordinator to ensure strict compliance with the protocol.

The ERAS group

Patients in the ERAS group received all elements of the ERAS protocol (figure 2)

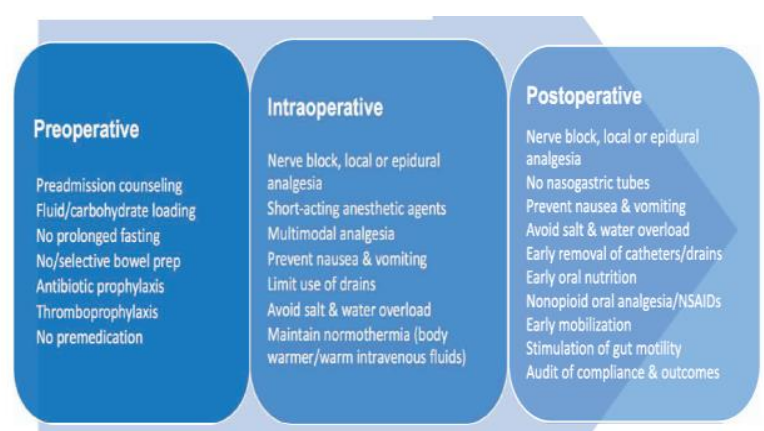

Figure2: Details of ERAS Protocol (Brown JK et al, 2018)

- The pars of preoperative enhanced recovery after surgery protocol

Education:

Patients and their families in the ERAS group received a detailed explanation about causes and risk factors of CAD disease, early ambulation after surgery, infection prevention, and secondary disease prevention. The researcher conducted the education and psychological counseling to alleviate patient anxiety and to improve patient compliance.

Perioperative education plays an important role in the ERAS program, and educating patients (Mc Connell G et al, 2018).

Fasting:

Decreasing the preoperative fasting period increases patient comfort. The fasting time was reduced to $6 \mathrm{~h}$ rather than the conventional $12 \mathrm{~h}$.

\section{Nutrition:}

It has been shown that iron or rh EPO reduce postoperative anemia and usage of red blood cells (Weltert $L$ et al 2015, Enko $D$ et al 2013, \& Ranucci $M$ etal 2011). The patient received preoperative iron or rh EPO.

Prophylactic antibiotics:

Prophylactic antibiotics were administered within 60 min of surgical incision

Intraoperative components of the enhanced recovery after surgery Anesthesia:

- The patients received standardized premedication with $0.5 \mathrm{mg} / \mathrm{kg}$ oral midazolam and $10 \mathrm{mcg} / \mathrm{kg}$ atropine.

- Induction of anesthesia was with sevo-flurane plus fentanyl $5.0 \mathrm{mcg} / \mathrm{kg}$ and cisatracurium $0.1 \mathrm{mg} / \mathrm{kg}$

- Maintenance of anesthesia was with sevoflurane, fentanyl $1.0 \mathrm{mcg} / \mathrm{kg} / \mathrm{h}$, and cisatracurium 0.05 $\mathrm{mg} / \mathrm{kg} / \mathrm{dose}$.

- Electrocardiogram, invasive blood pressure, heart rate, temperature, oxygen saturation, exhaled $\mathrm{CO} 2$ (end-tidal-capnography) were monitored.

\section{Ventilation:}

In effort to prevent lung injury and atelectasis, after mechanical ventilation was initiated for patients, a 
lung protection strategy, including low tidal volume ventilation and positive end-expiratory pressure in addition to lung recruitment maneuvers during the entire operation, was used. (Hemmes SN et al 2013) Cardiopulmonary bypass (CPB):

All patients in the two groups received standardized Management strategy of cardiopulmonary bypass (CPB).

- Before initiation of CPB:

The circuit of CPB was primed with mannitol, sodium bicarbonate, and packed red cells to obtain a hematocrit $26 \%$. Each patient was given Heparin $400 \mathrm{IU} / \mathrm{kg}$, and when activated clotting time reached Z 450 seconds, CPB was initiated.

- Cross clamping:

In cross clamping, the aorta was clamped, and cold blood cardio-plegia was administered into the aortic root and the patient cooled to $301 \mathrm{C}$ to $321 \mathrm{C}$. Each twenty minutes, the cardioplegia solution was repeated. The alpha-stat method of acid-base management was used. A mean arterial pressure was maintained between 30 to $60 \mathrm{mmHg}$ during CPB.

- Rewarming:

At the end of the intra-cardiac procedure, rewarming was started, aortic cross clamp was removed, and if spontaneous normal sinus rhythm was not present, pacing or defibrillation was performed depending on heart rate and rhythm. Ventilation was started, hemodynamics and arterial blood gases were stabilized, and patients were weaned from $\mathrm{CPB}$ at $37 \mathrm{1C}$. Protamine was administered to reverse heparin in a dose of $1 \mathrm{mg}$ protamine for every 100 IU heparin.

\section{Blood transfusion:}

As patients' haemoglobin was below $8 \mathrm{~g} / \mathrm{dl}$, red blood cells were transfused.

Postoperative comonents of the enhanced recovery after surgery protocol

- Patients received an additional $20 \mathrm{ml}$ of $0.25 \%$ ropivacaine around the incision site.

- To avoid postoperative nausea and vomiting, Ondansetron was used.

- Within $2 \mathrm{~h}$ of extubation, oral fluid was commenced

- A full diet was started on the 1st day after extubation in the intensive care unit (ICU).

- Urinary catheters and thoracic drainage tubes were removed as soon as possible on postoperative day 1 instead of on postoperative day 2 or 3 as in the control group.

- Patients were encouraged to ambulate as soon as possible.

\section{Pain management}

- Patient's pain was assessed by visual analogue scale three times by ICU nurse.

- For patients with pain score $>4$, nurses would taught them breathing exercises.

- Doctors would adjust analgesic strategy if necessary based on the hospital pain control protocol.

\section{Early mobilization}

Doctors and the researcher assessed patients' readiness for early mobilization procedure

As patients were allowed to ambulate at an early stage, the researcher explained and assisted the patients to perform all ambulation steps as follow:

- Moving the compression devices applied to legs

- Then, patients dangled on the edge of the bed on the first day after surgery.

- Then, they implemented active range of motion exercises at this position.

- Before getting off bed, the researcher assessed all devices for secure attachments, stopped unnecessary intravenous infusions, and moved indwelling devices to the side of the bed. Once the safety of all devices was confirmed, the health-care team assisted the patients to the side of the bed.

Early extubation of unnecessary tubes

The researcher and the physician judged patients' readiness for a spontaneous breathing trial within 4-6 hours of arrival in the ICU. When patients regained consciousness, the physicians, the researcher initiated a spontaneous breathing trial and determined readiness to extubation after $30 \mathrm{~min}$. When the blood gas analysis was normal, nurses would extubate the tube.

The control group:

Patients in the control group received the routine perioperative care.

Ethical consideration:

- The study followed common ethical principles in clinical principles in clinical research and was approved by the local ethics.

- Informed consent was taken from the head of manager of cardiac hospital and postoperative cardiac surgery ICU as well as patients to carry out this study.

\section{Pilot study}

A pilot study carried out on number of six patients $(10 \%)$ to test the applicability of the tools and appropriate study modification was done prior to data collection for the actual study; (the six patients were excluded from the sample).

\section{Statistical analysis}

Data were computerized and analyzed by computer programmed SPSS (ver.16). Quantitative data were 
compared using independent samples t-test for comparing two groups. Qualitative variables were compared using chi-square test to determine Significance. The sample size was calculated using Statistics Analysis System 9.4 (SAS Institute Inc.,

\section{Result:}

Table (1): Distribution of personal data For Studies groups

\begin{tabular}{|c|c|c|c|c|c|c|}
\hline \multirow{2}{*}{\multicolumn{2}{|c|}{ Age aroun Mean+SD }} & \multicolumn{2}{|c|}{ Control(n=30) } & \multicolumn{2}{|c|}{ ERAS $(n=30)$} & P. value \\
\hline & & \multicolumn{2}{|c|}{$42.65 \pm 11.79$} & \multicolumn{2}{|c|}{$42.2 \pm 13.03$} & 0.649 \\
\hline \multirow[t]{2}{*}{$\operatorname{Sex}(\%)$} & Male & 18 & $60 \%$ & 14 & $46.67 \%$ & \multirow[b]{2}{*}{0.982} \\
\hline & Female & 12 & $40 \%$ & 16 & $53.33 \%$ & \\
\hline \multicolumn{2}{|c|}{ Height Mean \pm SD } & \multicolumn{2}{|c|}{$162.11 \pm 6$} & \multicolumn{2}{|c|}{$160.23 \pm 9.12$} & 0.15 \\
\hline \multicolumn{2}{|c|}{ Weight Mean \pm SD } & \multicolumn{2}{|c|}{$71.63 \pm 19.56$} & \multicolumn{2}{|c|}{$68.23 \pm 15.33$} & 0.130 \\
\hline \multicolumn{2}{|c|}{ BMI Mean \pm SD } & \multicolumn{2}{|c|}{$27.28 \pm 6.41$} & \multicolumn{2}{|c|}{$26.92 \pm 5.38$} & 0.371 \\
\hline
\end{tabular}

Table( 2): Distribution of clinical data For Studies groups

\begin{tabular}{|c|c|c|c|c|c|}
\hline & \multicolumn{2}{|c|}{ Control $(n=30)$} & \multicolumn{2}{|c|}{ ERAS $(n=30)$} & \multirow{2}{*}{ P. value } \\
\hline & No. & $\%$ & No. & $\%$ & \\
\hline \multicolumn{6}{|l|}{ Medical diagnosis } \\
\hline Aortic valve replacement & 5 & 16.7 & 3 & 10 & \multirow{4}{*}{0.830} \\
\hline Coronary artery bypass graft & 11 & 36.7 & 11 & 36.67 & \\
\hline Double valve replacement & 4 & 13.3 & 3 & 10 & \\
\hline mitral valve replacement & 10 & 33.33 & 12 & 40 & \\
\hline \multicolumn{6}{|l|}{ American society of anesthesiology physical status of the patients } \\
\hline Healthy person & 0 & & 0 & & \multirow[t]{6}{*}{0.71} \\
\hline Mild systemic disease & 14 & 46.66 & 14 & 46.66 & \\
\hline patient with severe systemic disease & 7 & 23.33 & 8 & 26.66 & \\
\hline $\begin{array}{l}\text { patient with severe systemic disease that is a constant threat to } \\
\text { life }\end{array}$ & 4 & 13.33 & 5 & 16.66 & \\
\hline $\begin{array}{l}\text { moribund patient who is not expected to survive without the } \\
\text { operation }\end{array}$ & 5 & 16.66 & 5 & 16.66 & \\
\hline $\begin{array}{l}\text { declared brain-dead patient whose organs are being removed for } \\
\text { donor purposes }\end{array}$ & 0 & & 0 & & \\
\hline \multicolumn{6}{|l|}{ past history } \\
\hline No & 12 & 40.0 & 11 & 36.67 & \multirow{3}{*}{0.595} \\
\hline Diabetes \& hypertension & 5 & 16.7 & 7 & 23.33 & \\
\hline Rheumatic Heart & 13 & 43.3 & 12 & 40 & \\
\hline
\end{tabular}

Chi-square test *Statistically Significant difference At P. value $<0.05$.independent $T$ - test

*Statistically Significant difference At P. value $<0.05$

Table (3): comparison of intra-operative and blood transfusion data For Studies groups

\begin{tabular}{|c|c|c|c|c|}
\hline & $\operatorname{Control}(n=30)$ & $\operatorname{ERAS}(\mathbf{n}=30)$ & P. value \\
\hline \multicolumn{2}{|c|}{ operation time in hour Mean \pm SD } & $7.07 \pm 1.08$ & $6.23 \pm 0.61$ & $<0.001 * *$ \\
\hline \multicolumn{2}{|c|}{ Ischemic time in minutes Mean \pm SD } & $82.60 \pm 29.75$ & $82.71 \pm 16.43$ & 0.77 \\
\hline \multicolumn{2}{|c|}{ bypass time in minutes Mean \pm SD } & $144.97 \pm 18.94$ & $122 \pm 22.61$ & 0.060 \\
\hline \multirow{2}{*}{$\begin{array}{l}\text { Intra-operative } \\
\text { Blood transfusion }\end{array}$} & Plasma Mean \pm SD & $675.93 \pm 160.2$ & $570.2 \pm 132.9$ & 0.010* \\
\hline & Blood Mean \pm SD & $676.4 \pm 146.9$ & $596.16 \pm 162.61$ & 0.175 \\
\hline \multirow{2}{*}{$\begin{array}{l}\text { Day of operation } \\
\text { Blood transfusion }\end{array}$} & Plasma Mean \pm SD & $465.8 \pm 214.1$ & $350.0 \pm 187$ & 0.135 \\
\hline & Blood Mean \pm SD & $447.5 \pm 240.3$ & $363.6 \pm 130.6$ & 0.218 \\
\hline
\end{tabular}

Independent T test *Statistically Significant difference At P. value $<0.05$,

**Statistically Significant difference At P. value $<0.01$ 
Table( 4): Comparison between Studies groups According to outcomes Parameters

\begin{tabular}{|c|c|c|c|c|c|c|}
\hline \multicolumn{2}{|c|}{ 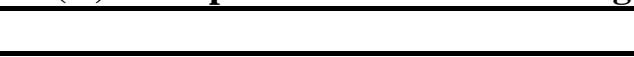 } & \multicolumn{2}{|c|}{ Control $(n=30)$} & \multicolumn{2}{|c|}{$\operatorname{ERAS}(\mathbf{n}=30)$} & P. value \\
\hline \multicolumn{2}{|c|}{$\begin{array}{l}\text { Duration of mechanical ventilation } \\
\text { Mean } \pm \text { SD }\end{array}$} & \multicolumn{2}{|c|}{$4.64 \pm 2.13$} & \multicolumn{2}{|c|}{$2.33 \pm 0.81$} & $<0.001 * *$ \\
\hline \multirow{2}{*}{$\begin{array}{l}\text { Wound infection } \\
(\%)\end{array}$} & no & 30 & $100 \%$ & 30 & $100 \%$ & \multirow[b]{2}{*}{-} \\
\hline & yes & 0 & 0 & 0 & 0 & \\
\hline \multirow{2}{*}{$\begin{array}{l}\text { Post-operative } \\
\text { bleeding }(\%)\end{array}$} & yes & 11 & $36.67 \%$ & 3 & $10 \%$ & \multirow{2}{*}{$0.03 *$} \\
\hline & no & 19 & $63.33 \%$ & 27 & $90 \%$ & \\
\hline \multirow[t]{2}{*}{ Re-intubation (\%) } & Yes & 5 & $16.7 \%$ & 1 & $3.33 \%$ & \multirow{2}{*}{$0.031 *$} \\
\hline & No & 25 & $83.3 \%$ & 29 & $96.66 \%$ & \\
\hline \multicolumn{2}{|l|}{ ICU stay Mean \pm SD } & \multicolumn{2}{|c|}{$\frac{1}{5.82 \pm 0.61}$} & \multicolumn{2}{|c|}{$3.04 \pm 0.74$} & $<0.001 * *$ \\
\hline
\end{tabular}

Chi-square test ${ }^{*}$ Statistically Significant difference At P. value $<0.05$, Independent $T$ - test

${ }^{*}$ Statistically Significant difference At P. value $<0.05$, **Statistically Significant difference At P. value $<0.01$

Table (5): Relationship between Studies groups According to Pain assessment

\begin{tabular}{|c|c|c|c|c|c|}
\hline & \multicolumn{2}{|c|}{$\operatorname{Control}(n=30)$} & \multicolumn{2}{|c|}{ ERAS $(n=30)$} & \multirow{2}{*}{ P. value } \\
\hline & No. & $\%$ & No. & $\%$ & \\
\hline \multicolumn{6}{|c|}{ Day of operation } \\
\hline Mild & 2 & 6.66 & 6 & 20 & \multirow{3}{*}{$<0.001 * *$} \\
\hline Moderate & 4 & 13.33 & 14 & 46.66 & \\
\hline Sever & 24 & 80 & 10 & 33.33 & \\
\hline \multicolumn{6}{|l|}{ Day1 } \\
\hline Mild & 3 & 6.7 & 15 & 50.0 & \multirow{3}{*}{$0.001 * *$} \\
\hline Moderate & 22 & 70.0 & 10 & 30.0 & \\
\hline Sever & 5 & 23.3 & 5 & 20.0 & \\
\hline \multicolumn{6}{|l|}{ Day2 } \\
\hline Mild & 10 & 33.33 & 18 & 72.0 & \multirow{3}{*}{$0.003 * *$} \\
\hline Moderate & 20 & 67.33 & 12 & 28.0 & \\
\hline Sever & 0 & 0 & 0 & 0.0 & \\
\hline \multicolumn{6}{|l|}{ Day3 } \\
\hline Mild & 15 & 50 & 30 & 100.0 & \multirow{3}{*}{0.515} \\
\hline Moderate & 15 & 50 & 0 & 0.0 & \\
\hline Sever & 0 & 0 & 0 & 0.0 & \\
\hline \multicolumn{6}{|l|}{ Day4 } \\
\hline Mild & 29 & 96.67 & 1 & 100.0 & \multirow{2}{*}{0.505} \\
\hline Moderate & 1 & 3.33 & 0 & 0.0 & \\
\hline
\end{tabular}

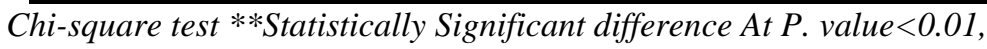

Table( 6): Frequencies of studies groups according to time of first mobilization

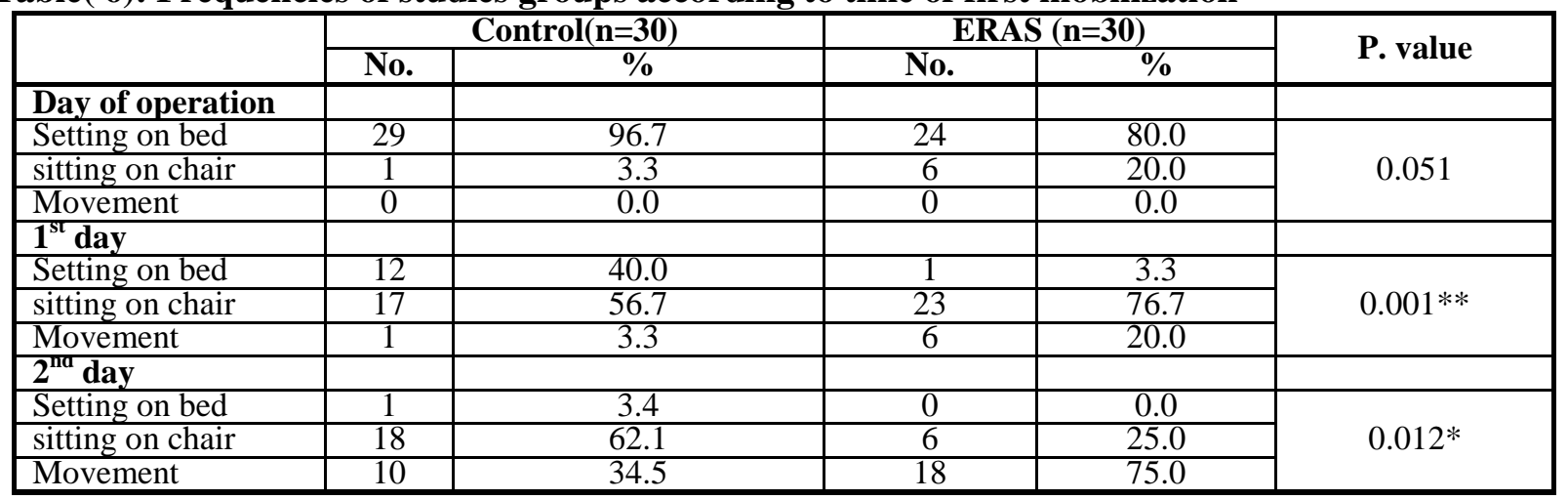




\begin{tabular}{|l|c|c|c|c|c|}
\hline \multirow{2}{*}{} & \multicolumn{2}{|c|}{ Control(n=30) } & \multicolumn{2}{c|}{ ERAS (n=30) } & \multirow{2}{*}{ P. value } \\
\cline { 2 - 5 } & No. & \% & No. & \% & \\
\hline $3^{\text {ra day }}$ & & & & & \multirow{2}{*}{0.168} \\
\hline Setting on bed & 0 & 0.0 & 1 & 0.0 & \\
\hline sitting on chair & 1 & 5.3 & 6 & 71.4 & \\
\hline Movement & 18 & 94.7 & & & \\
\hline $4^{\text {III day }}$ & & & 0 & 0 & \\
\hline Setting on bed & 0 & 0 & 0 & 0 & \multirow{2}{*}{-} \\
\hline sitting on chair & 0 & 0 & 1 & 100.0 & \\
\hline Movement & 1 & 100.0 & & \\
\hline
\end{tabular}

Chi-square test $\quad$ *Statistically Significant difference At P. value $<0.05$,

Table (7):- Relationship between Studies groups According to quality of life and VAS 2 week After Surgery

\begin{tabular}{|c|c|c|c|c|c|}
\hline \multirow{2}{*}{2 Week post-surgery } & \multicolumn{2}{|c|}{ Control $(n=30)$} & \multicolumn{2}{|c|}{ ERAS $(\mathbf{n}=30)$} & \multirow{2}{*}{ P. value } \\
\hline & No. & $\%$ & No. & $\%$ & \\
\hline \multicolumn{6}{|l|}{ Mobility } \\
\hline No problem & 2 & 6.7 & 11 & 40.0 & \multirow{3}{*}{$0.002 *$} \\
\hline Some problem & 25 & 83.33 & 18 & 60.0 & \\
\hline Extreme problem & 2 & 6.7 & 1 & 3.3 & \\
\hline \multicolumn{6}{|l|}{ Self-Care } \\
\hline No problem & 3 & 10 & 10 & 30.0 & \multirow{3}{*}{$0.005 * *$} \\
\hline Some problem & 23 & 76.66 & 20 & 70.0 & \\
\hline Extreme problem & 4 & 13.3 & 0 & 0.0 & \\
\hline \multicolumn{6}{|l|}{ Activities } \\
\hline No problem & 3 & 10 & 10 & 30.0 & \multirow{3}{*}{$0.010 *$} \\
\hline Some problem & 27 & 90.0 & 20 & 70.0 & \\
\hline Extreme problem & 0 & 0 & 0 & 0.0 & \\
\hline \multicolumn{6}{|l|}{ Pain } \\
\hline No problem & 1 & 3.3 & 9 & 33.3 & \multirow{2}{*}{$0.003 * *$} \\
\hline Some problem & 29 & 96.7 & 21 & 66.7 & \\
\hline \multicolumn{6}{|l|}{ Anxiety } \\
\hline No problem & 1 & 3.3 & 0 & 0 & \multirow{2}{*}{0.085} \\
\hline Some problem & 29 & 96.7 & 30 & 100 & \\
\hline Scale means \pm SD & \multicolumn{2}{|c|}{$80.31 \pm 6.68$} & \multicolumn{2}{|c|}{$83.5 \pm 9.11$} & 0.236 \\
\hline
\end{tabular}

Chi-square test, Independent T- test ${ }^{*}$ Statistically Significant difference At P. value $<0.05$

Table (8): Relationship between studies groups according to quality of life and VAS 6 week after surgery

\begin{tabular}{|c|c|c|c|c|c|}
\hline \multirow{2}{*}{6 Week post-surgery } & \multicolumn{2}{|c|}{$\operatorname{Control}(n=30)$} & \multicolumn{2}{|c|}{ ERAS $(n=30)$} & \multirow{2}{*}{ P. value } \\
\hline & No. & $\%$ & No. & $\%$ & \\
\hline \multicolumn{6}{|l|}{ Mobility } \\
\hline No problem & 30 & 100.0 & 30 & 100.0 & - \\
\hline \multicolumn{6}{|l|}{ Self-Care } \\
\hline No problem & 30 & 100.0 & 30 & 100.0 & - \\
\hline \multicolumn{6}{|l|}{ Activities } \\
\hline No problem & 8 & 26.7 & 27 & 90 & \multirow{2}{*}{$<0.001 * *$} \\
\hline Some problem & 22 & 73.3 & 3 & 10 & \\
\hline \multicolumn{6}{|l|}{ Pain } \\
\hline No problem & 20 & 73.3 & 29 & 96.66 & \multirow{2}{*}{$<0.001 * *$} \\
\hline Some problem & 10 & 26.7 & 1 & 3.33 & \\
\hline \multicolumn{6}{|l|}{ Anxiety } \\
\hline No problem & 30 & 100.0 & 30 & 100.0 & \multirow[b]{2}{*}{-} \\
\hline Some problem & 0 & 0 & 0 & 0 & \\
\hline Scale $6 w$ means \pm SD & \multicolumn{2}{|c|}{$88.17 \pm 3.34$} & \multicolumn{2}{|c|}{$91.27 \pm 3.03$} & $<0.001 * *$ \\
\hline
\end{tabular}

Chi-square test, Independent T- test ${ }^{*}$ *Statistically Significant difference At P. value $<0.01$ 
Table (1): Shows the personal characteristics of the two groups. Regarding to the age it was found that the means \pm SD of age was $(43.67 \pm 11.79 \& 42.2 \pm$ $13.03)$ in control group and ERAS group respectively. Regarding to the sex it was found that males were $60 \%$ in control group versus $53.33 \%$ were female in study group. Regarding to height it was found that the means \pm SD of height was (162.11 $\pm 6 \& 160.23 \pm 9.12$ ) in control and ERAS group respectively. According to weight it was found that the means \pm SD of weight was $(71.63 \pm 19.56 \& 68.23$ \pm 15.33 ) in control and in ERAS respectively. For body mass index it was found that the means \pm SD of body mass index was $(27.28 \pm 6.41 \& 25.92 \pm 5.38)$ in control group and ERAS respectively. The result revealed that no statistical difference between both groups in all data.

Table (2): Shows the clinical characteristics of the two groups. Regarding to medical diagnosis it was found that CABG was equal in both groups (36.67\%). Regarding to American society of anesthesiology physical status of the patients (ASA), results revealed that the majority of patients $(46.66 \%)$ were patient with mild systemic disease in the control and ERAS group. For the past history the results revealed that $(43.3 \%)$ of the control and $(40 \%)$ of the ERAS had rheumatic heart. without statistically significant between all the study groups $(\mathrm{P}>0.05)$.

Table (3): In the relation to the operation times in hours the results revealed that the means \pm SD was $(7.07 \pm 1.08 \& 6.23 \pm 0.61)$ in control group and ERAS respectively with a significant statistical differences between both groups ( $\mathrm{P}$ value $<0.05$ ). For ischemic time in minutes the means \pm SD was $(82.60$ $\pm 29.75 \& 82.71 \pm 16.43$ ) in control and ERAS group respectively. Regarding bypass time in minutes the means \pm SD was $(144.97 \pm 18.94 \& 122 \pm 22.61)$ for control and ERAS group respectively ( $\mathrm{P}$ value <0.05). Regarding to Intra-operative plasma transfusion, the means \pm SD was $(675.93 \pm 160.2 \&$ $570.2 \pm 132.9)$ in control, and ERAS group with a significant statistical differences between both groups ( $\mathrm{P}$ value $<0.05)$. Regarding to intra-operative blood transfusion, the means \pm SD was $(676.4 \pm 146.9$ \&596.16 \pm 162.61$)$ in control, and in ERAS group respectively. Regarding to Day of operation plasma transfusion, the means \pm SD was $(465.8 \pm 214.1 \&$ $350.0 \pm 187)$ in control, and in ERAS group respectively. Regarding to Day of operation blood transfusion the means \pm SD was $(447.5 \pm 240.3 \&$ $363.6 \pm 130.6)$ in control, and in ERAS group respectively.

Table (4): Shows the outcomes parameters in both groups: regarding to duration of mechanical ventilation, the means \pm SD was $(4.64 \pm 2.13 \& 2.33 \pm$ 0.8 ) in control and the ERAS respectively with significance difference between both groups. All patients didn't have any wound infection. Regarding to post-operative bleeding, $36.67 \%$ of patient in the control group versus $10 \%$ of patients in the ERAS group had bleeding with significant difference ( $\mathrm{P}$ value $<0.05$ ). As regard to re intubation, $16.66 \%$ in control while $3.33 \%$ in ERAS re-intubated with significance difference between both groups. Regarding to the intensive care unit stay it was found that the means $\pm \mathrm{SD}$ in control group was $5.82 \pm 0.61$ and the means \pm SD in ERAS was $3.04 \pm 0.74$ with statistical differences between both groups

Table (5): Shows the relationship between studies groups according to pain assessment. This table demonstrates that, there was statistical significance difference between both groups according to pain level at day of operation, $80 \%$ in control had severe pain versus $33.33 \%$ in ERAS. There was statistical significance difference between both groups according to pain level at day $170 \%$ in control versus $30 \%$ in ERAS had moderate pain. There was statistical significance difference between both groups according to pain level at day 2. $33.33 \%$ in control versus $72 \%$ in ERAS had mild pain.

Table (6): Shows frequencies of studies groups according to time of first mobilization. This table demonstrates that, according to the first mobilization at 1 st day $20 \%$ in ERAS versus $3.3 \%$ in control group moved from bed with a significant difference. While at the 2nd day of operation, movement was 75 $\%$ in ERAS, while $34.5 \%$ in control with a significant difference

Table (7): This table show that, assessment of quality of life 2 weeks after surgery were statistical significant at mobility, self-care, activities and pain. Regarding to mobility, $(6.7 \%$ and $40 \%)$ in control and ERAS group respectively didn't have any problem in mobility. Regarding to self-care \& activity, (10\% and $30 \%)$ in control and ERAS group respectively didn't have any problem. Regarding to pain, $(3.3 \%$ and $33.3 \%$ ) in control and ERAS group respectively didn't have any pain.

Table (8): This table shows that, assessment of quality of life 6 weeks after surgery were statistical significant at activities, pain and anxiety. Regarding to pain, $(26.7 \%$ and $3.33 \%)$ in control and ERAS group respectively had pain. There were statistically significance difference between two groups as regard EQ VAS scale 6 weeks after surgery the highest mean was 88.17 \pm 3.34 in ERAS, and in control was $91.27 \pm 3.03$.

\section{Discussion}

A series of clinical trials and meta-analyses have confirmed the effectiveness of ERAS in a variety of 
non-cardiac surgeries (Grantcharov TP \& Kehlet H, 2010). So this study conducted to confirm its effect on cardiac surgery.

Regarding patient demographics and other characteristics, the patients were similar in age, gender, BMI, American Society of Anesthesiologists (ASA) physical status in both groups. These findings were in line with (Li M etal 2018).

The evidence-based guidelines of various surgical procedures have been published by the international ERAS $®$ Society (www.erassociety.org). Several studies by Greco M etal 2014, Joliat G-R, etal 2015 reported that the implementation of ERAS guidelines reduce postoperative complications, length of stay (LOS) and overall costs, and increase both patient and staff satisfaction. These reports were in line with our study which showed that duration of ICU stay in the ERAS group were significantly shorter than the corresponding values in the control group. These could be explained by that all elements of ERAS lead to faster recovery. Also (Thiele R.H etal,2015) mentioned that after ER-protocol implementation on patients undergoing colorectal surgery, the actual length of ICU stay (LOS) was 0.6 days less than the predicted LOS. This corresponded to a 2.2-day reduction in adjusted LOS ( $p<0.0001)$. Some previous studies (G. Nelson et al, 2016, Angus $M$ et al, 2019, Dagal A et al 2018 \& Carr DA et al, 2019) mentioned that the application of ERAS protocol decreased the LOS. For (Debono B et al 2019) hospital LOS was not changed by the application of an ERAS protocol and this was attributed to poor compliance/protocol adherence.

There are many studies have shown that the ERAS protocol can reduce intubation time, for patients undergoing cardiac surgery(Zaouter $\mathrm{C}$ et al, 2019, Williams JB et al, 2019 \& Li M et al 2018). These results matched with our study that has shown a significant decrease in MV duration and re-intubation rate in the ERAS group rather than control group. This may be attributed to the early mobilization or good compliance with other element of ERAS protocol. While these results were in contrast to (Chen L etal, 2020) who showed that the average extubation time of the tracheal tube was $8.72 \mathrm{~h}$ in the routine care group and $7.59 \mathrm{~h}$ in the ERAS group without significant difference.

ERAS puts the patient in the center of its perioperative management and recovery team and empowers him or her by increasing motivation to recover quickly and accepting responsibilities in their own management and recovery plan. In major gynecologic surgery, a before-and-after ERAS implementation study reported significantly better pain control and better patient information (Hughes $M$ et al 2015 \& Modesitt SC et al 2016). These reports were in line with the results of this study which showed that the ERAS protocol resulted in significant reduction in pain level in the day of operation, first and second day of operation. This may have been attributed to greater awareness of and importance of individual components of enhanced recovery pathways by the medical teams caring for patients and also to increased use of intraoperative fentanyl and morphine in the ERACS group. These results were matched with (Thiele R.H et al,2015) who stated that pain scores were lower on the day of colorectal surgery for both open and laparoscopic cases in the ER pathway as compared with the traditional pathway $(\mathrm{p}<0.001)$. Moreover d'Astorga H et al 2020 reported that level of pain decreased Early mobilization has been shown to promote recovery of physiological function (Uda K etal, 2018). The results of this study showed that the ERAS protocol resulted in increased ability to patients to move early. In this study, improvement in pain management made early ambulation possible. The SF-8 quality of- life questionnaires reflect patients' subjective feelings regarding their quality of life. In our study, the ERAS protocol caused a significant improvement in quality-of-life evaluation at 2 weeks and 6 weeks after surgery. This may be due to postoperative physical therapy and rehabilitation exercises in the ERAS programme could enable patients to resume their normal activities. This was in accordance with two recent reports also suggested that ERAS implementation may be associated with improved long-term survival (Gustafsson UO et al 2016 \& Savaridas T et al 2013). Moreover, Some studies have even suggested there is a survival benefit when patients are cared for with an ERAS pathway (T. Savaridas et al, 2013, G. Nelson et al, 2016 \& A. Visioni et al, 2017)

\section{Conclusions:}

This study demonstrates that patients undergoing cardiac surgery who received an ERAS protocol had a shorter length of ICU stay and duration of mechanical ventilation and less Post-operative bleeding and re intubation need. The authors

\section{Recommendation:}

Recommended conducting further larger, multicenter studies to validate the findings of this study.

\section{References}

- Visioni, R., Shah, E., Gabriel, K., Attwood, M., Kukar, S., \&Nurkin, (2018): Enhanced recovery after surgery for non-colorectal surgery?: a systematic review and meta-analysis of major abdominal surgery, Ann. Surg. Jan;267(1):57-65 
- Angus M., Jackson K., Smurthwaite G., Carrasco R., Mohammad S. \& Verma R, (2019): The implementation of enhanced recovery after surgery (ERAS) in complex spinal surgery. J Spine Surg;5:116-23.

- Brown JK., Karanbir Singh, Razvan Dumitru, \& Edward Chan (2018): The Benefits of Enhanced Recovery After Surgery Programs and Their Application in Cardiothoracic Surgery CME. METHODIST DEBAKEY CARDIOVASC J. 14 (2).

- Carr DA, Saigal R., Zhang F., Bransford RJ, Bellabarba C. \& Dagal A. (2019): Enhanced peri-operative care and decreased cost and length of stay after elective major spinal surgery. Neurosurg Focus; Apr 1;46(4)

- Chen L., Jing Zheng, Dong Kong, \& Lijuan Yang (2020): Effect of Enhanced Recovery After Surgery Protocol on Patients Who Underwent Off-Pump Coronary Artery Bypass Graft. Asian Nursing Research; 14, 44-49.

- Cohen R. \& Gooberman- Hill R (2019): Staff experiences of enhanced recovery after surgery: systematic review of qualitative studies. BMJ Open; Feb 12;9(2)

- D’astorga H., Vincent Fièrea, Maud Dupasquier, Thais Dutra Vieiraa \& Marc Szadkowski (2020): Enhanced recovery after surgery (ERAS) protocol reduces LOS without additional adverse events in spine surgery. Orthopaedics \& Traumatology: Surgery \& Research 106 1167-1173

- Dagal A., Bellabarba C., Bransford R., Zhang F., Chesnut RM, \& O'Keefe GE. (2019): Enhanced perioperative care for major spine surgery. Spine, Jul 1;44 (13):959966. .doi.org/10.1097/BRS.0000000000002968.

- Debono B., Corniola MV., Pietton R., Sabatier P, Hamel O., \& Tessitore E. (2019): Benefits of enhanced recovery after surgery for fusion in degenerative spine surgery: impact on outcome, length of stay, and patient satisfaction. Neurosurg Focus 46 (4):E6.

- Enko D., Wallner F., Von-Goedecke A., Hirschmugl C., Auersperg V. \& HalwachsBaumann G. (2013): The impact of an algorithm-guided management of preoperative anemia in perioperative hemoglobin level and transfusion of major orthopedic surgery patients. Anemia:641876.

- Fleming IO., Garratt C., \& Guha R. (2016): Aggregation of marginal gains in cardiac surgery: Feasibility of a perioperative care bundle for enhanced recovery in cardiac surgical patients. $\mathrm{J}$ Cardiothorac Vasc Anesth;30:665-70.
- Nelson, G., Kiyang, L.N., Crumley, E.T., Chuck, A., Nguyen, T., \& Faris, P. (2016): Implementation of Enhanced Recovery After Surgery (ERAS) across a provincial healthcare system: the ERAS Alberta colorectal surgery experience, World J. Surg. 40 (5) 1092-1103.

- Grant MC, Isada T, \& Ruzankin P (2019): Results from an enhanced recovery program for cardiac surgery [E-pub ahead of print]. J Thorac Cardiovasc Surg Apr;159(4):1393-1402.

- Grantcharov TP., \& Kehlet H. (2010): Laparoscopic gastric surgery in an enhanced recovery programme. Br J Surg;97:1547-51.

- Greco M., Capretti G. \& Beretta L. (2014): Enhanced recovery program in colorectal surgery: a meta-analysis of randomized controlled trials. World J Surg.;38:1531-41.

- Gregory A.J, Michael C., Grant, Michael W. Manning, Albert T. Cheung, Joerg Ender, Michael Sander, Alexander Zarbock, Christian Stoppe, Massimiliano Meineri, Hilary P. Grocott, Kamrouz Ghadimi, Jacob T. Gutsche, Prakash A. Patel, Andre Denault, Andrew Shaw, Nick Fletcher, \& Jerrold H. Levy (2020) : Enhanced Recovery After Cardiac Surgery (ERAS Cardiac) Recommendations: An Important First Step-But There Is Much Work to Be Done. Journal of Cardiothoracic and Vascular Anesthesia 34, 39_47

- Gustafsson UO., Oppelstrup H. \& Thorell A., (2016): Adherence to the ERAS protocol is associated with 5-year survival after colorectal Cancer surgery: a retrospective cohort study. World J Surg.;40:1741-7.

- Hemmes SN., Serpa NA., \& Schultz MJ. (2013): Intraoperative ventilatory strategies to prevent postoperative pulmonary complications: a meta-analysis. Curr Opin Anaesthesiol;26:12633.

- Hughes M., Coolsen MME. \& Aahlin EK., (2015): Attitudes of patients and care providers to enhanced recovery after surgery programs after major abdominal surgery. J Surg Res.;193:10210.

- Hughes MJ, McNally S, Wigmore SJ (2014): Enhanced recovery following liver surgery: a systematic review and meta-analysis. HPB.;16:699-706.

- Joliat G-R., Labgaa I. \& Petermann D., (2015): Cost-benefit analysis of an enhanced recovery protocol for pancreatico-duodenectomy. $\mathrm{Br} \mathrm{J}$ Surg.; 102:1676-83.

- Joliat GR., Olle L., Tracy W., Oliver P. \& Nicolas D. (2018): Beyond surgery: clinical and economic impact of Enhanced Recovery After 
Surgery programs. BMC Health Services Research,. 18:1008

- Kehlet H. (1997): Multimodal approach to control postoperative pathophysiology and rehabilitation. Br J Anaesth;78:606-17.

- Li M., Zhang J., \& Gan TJ., (2018): Enhanced recovery after surgery pathway for patients undergoing cardiac surgery: A randomized clinical trial. Eur J Cardiothorac Surg;54:491-7.

- Markham T., Wegner R., \& Hernandez N., (2018): Assessment of a multimodal analgesia protocol to allow the implementation of enhanced recovery after cardiac surgery: Retrospective analysis of patient outcomes. J Clin Anesth; 54:76-80.

- McConnell G., Woltz P., Bradford WT., Ledford JE, \& Williams JB. (2018): Enhanced recovery after cardiac surgery program to improve patient outcomes. Nursing. 48(11):24e31.

- Modesitt SC., Sarosiek BM., Trowbridge ER., (2016): Enhanced recovery implementation in major gynecologic surgeries: effect of care standardization. Obstet Gynecol.;128:457-66.

- Noss C., Prusinkiewicz C.\& Nelson G. (2018): Enhanced recovery for cardiac surgery. J Cardiothorac Vasc Anesth; 32:2760-70.

- Ranucci M., Aronson S., Dietrich W., Dyke CM., Hofmann A. \& Karkouti K. (2011): Patient blood management during cardiac surgery: do we have enough evidence for clinical practice? J Thorac Cardiovasc Surg; 142:249.e1-32.

- Savaridas T., Serrano-Pedraza I. \& Khan SK. (2013): Reduced medium-term mortality following primary total hip and knee arthroplasty with an enhanced recovery program. A study of 4,500 consecutive procedures. Acta Orthop.; 84:40-3.

- Scott MJ., Baldini G., Fearon KC., Feldheiser A., Feldman LS., \& Gan TJ. (2015): Enhanced recovery after surgery (ERAS) for gastrointestinal surgery, part 1: pathophysiological considerations. Acta Anaesthesiol Scand; 59: 1212-31.

- Smith J., Probst S., Calandra C., Davis R., Sugimoto K. \& Nie L. (2019): Enhanced recoveryafter surgery (ERAS) program for lumbar spine fusion. Perioper Med (Lond); 8:4.

- Savaridas, T., Serrano-Pedraza, I. Khan, S.K., K.Martin, A. \&Malviya, M.R. (2013): Reduced medium-term mortality following primary total hip and knee arthroplasty with an enhanced recovery program: a study of 4,500 consecutive procedures, Acta Orthop. 84 (1) 40-43.

- Thiele R.H., Kathleen M., Rea, Florence E Turrentine, Charles M., Friel, Taryn E
Hassinger, MD, Bernadette J Goudreau, BS, Bindu A Umapathi, MD, Irving L Kron, MD,FACS, RobertGSawyer, Traci L Hedrick, Timothy L \& McMurry (2015): Standardization of Care: Impact of an Enhanced Recovery Protocol on Length of Stay, Complications, and Direct Costs after Colorectal Surgery. J Am Coll Surg;220:430 - 443

- Varadhan KK., Lobo DN. \& Ljungqvist O. (2010): Enhanced recovery after surgery: the future of improving surgical care. Crit Care Clin;26:527-47.

- Weltert L., Rondinelli B., Bello R., Falco M., Bellisario A. \& Maselli D. (2015): A single dose of erythropoietin reduces perioperative transfusions in cardiac surgery: results of a prospective single-blind randomized controlled trial. Transfusion;55:1644-54.

- Wewers ME, \& Lowe NK. (1990): A critical review of visual analogue scales in the measurement of clinical phenomena. Res Nurs Health;13:227-36.

- Williams JB., McConnell G., Allender JE., Woltz P., Kane K. \& Smith PK., (2019): One year results from the first US-based enhanced recovery after cardiac surgery (ERAS Cardiac) program. J Thorac Cardiov Sur.;157(5):1881e8. https://doi.org/10.1016/j.jtcvs.2018.10.164

- Zaouter C., Oses P., Assatourian S., Labrousse L., R_emy A. \& Ouattara A. (2019): Reduced length of hospital stay for cardiac surgery implementing an optimized perioperative pathway: prospective evaluation of an enhanced recovery after surgery program designed for miniinvasive aortic valve replacement. J Cardiothorac Vasc Anesth.; 33(11):3010e9. https://doi.org/10.1053/j.jvca.2019.05.006 